\title{
SHAKE TABLE TESTS FOR THE SEISMIC ASSESSMENT OF HOLLOW BRICK INTERNAL PARTITIONS
}

\author{
C. Petrone ${ }^{\mathrm{a}}$, G. Magliulo*b ${ }^{*}$ G. Manfredi ${ }^{\mathrm{c}}$ \\ ${ }^{a}$ University of Naples Federico II, Department of Structures for Engineering and Architecture, via Claudio 21, 80125 Naples, \\ Italy,crescenzo.petrone@unina.it \\ bUniversity of Naples Federico II, Department of Structures for Engineering and Architecture, via Claudio 21, 80125 Naples, \\ Italy,gmagliul@unina.it \\ 'University of Naples Federico II, Department of Structures for Engineering and Architecture, via Claudio 21, 80125 Naples, \\ Italy,gamanfre@unina.it
}

\begin{abstract}
The collapse of hollow brick internal partitions is one of the most widely reported nonstructural damage after an earthquake, especially in the European area. Full-scale experimental tests on standard hollow brick partitions are described in the paper. In particular, bidirectional shaking table tests are performed in order to investigate the seismic performance of hollow brick partitions, subjecting the partition simultaneously to interstorey relative displacements in their own plane and accelerations in the out of plane direction. A steel test frame is properly defined in order to simulate the seismic effects at a generic building storey. A set of five couples of accelerograms are selected matching the target response spectrum provided by the U.S. code for nonstructural components in order to investigate a wide range of seismic input. Three damage states are considered in this study and correlated to an engineering demand parameter, i.e. the interstorey drift ratio, through the use of a damage scheme. The tested specimen exhibits significant damage for $0.3 \%$ interstorey drift and extensive damage for drift close to $1 \%$. The correlation between the dynamic characteristics of the test setup, in terms of damping ratio and natural frequency, and the recorded damage is shown.
\end{abstract}

KEYWORDS: nonstructural component, hollow brick partitions, seismic performance, shake table test, infilled frame, dynamic identification

\footnotetext{
* corresponding author. University of Naples Federico II, Department of Structures for Engineering and Architecture, via Claudio 21, 80125 Naples, Italy, gmagliul@unina.it, tel. +39 081 7683656, fax. +39 0817685921.
} 


\section{INTRODUCTION}

Nonstructural components (NSCs) are those systems and components attached to the floors, roof and walls of a building or industrial facility that are not part of the main load-bearing structural system, but may also be subjected to large seismic actions [1]. The investigation of the seismic behaviour of NSC performance is nowadays recognised to be a key topic in the framework of the earthquake risk mitigation. The paper deals with internal partition systems, i.e. a typical architectural NSC.

Performance-based seismic engineering clearly includes the seismic performance of NSC in the assessment of the behaviour of the whole building system: the behaviour of both structural and nonstructural elements define the building seismic performance [2]. NSCs usually exhibit damage even for low-intensity earthquakes causing the evacuation of the whole building. Their seismic performance is critical especially for hospitals or strategic buildings, that should remain operative after an earthquake.

Taghavi and Miranda [3] point out that NSCs give the largest contribution to the total cost of a building; for this reason the NSCs contribution should not be neglected in the evaluation of the economic loss due to an earthquake. Their economic impact is much more severe if losses of inventory and downtime cost are considered: the cost related to nonstructural components failure may easily exceed the replacement cost of the building [4]. Moreover, the failure of nonstructural components may also represent a threat to life safety. A partition or infill overturning may easily cause injuries or casualties.

Few studies were conducted in the past on nonstructural components performance evaluation, particularly referring to suspended ceiling systems [5-7] and plasterboard partitions [8-11]. Very limited studies were conducted in the past on the seismic behaviour of hollow brick internal partitions, even though they are very common in the European area both in residential and industrial buildings [12, 13]. Furthermore, recent earthquakes demonstrated that brick partitions usually exhibit extensive damage jeopardizing the functionality of the whole building (Fig. 1). The high vulnerability of the hollow brick partitions may result in significant damages that are not acceptable in hospital buildings; San Salvatore hospital in L'Aquila (Fig. 1b), struck by L'Aquila earthquake in 2009, clearly showed this issue.

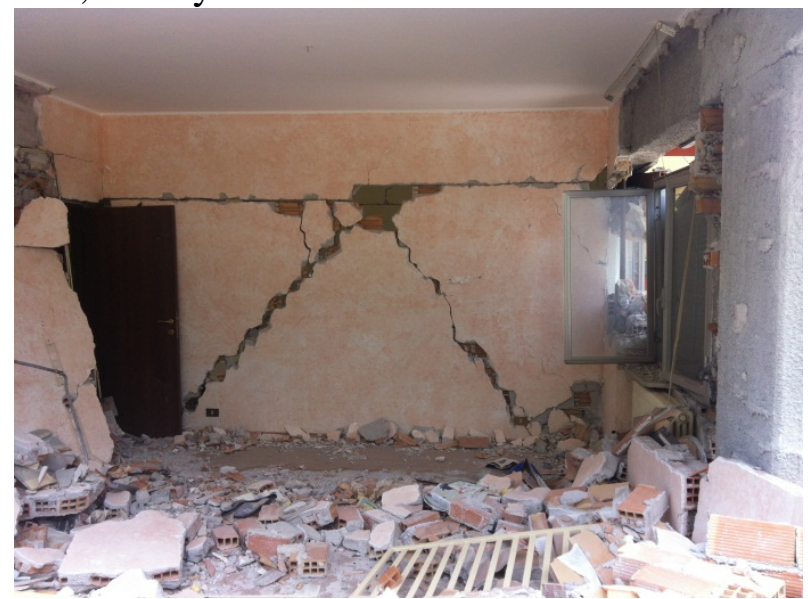

(a)

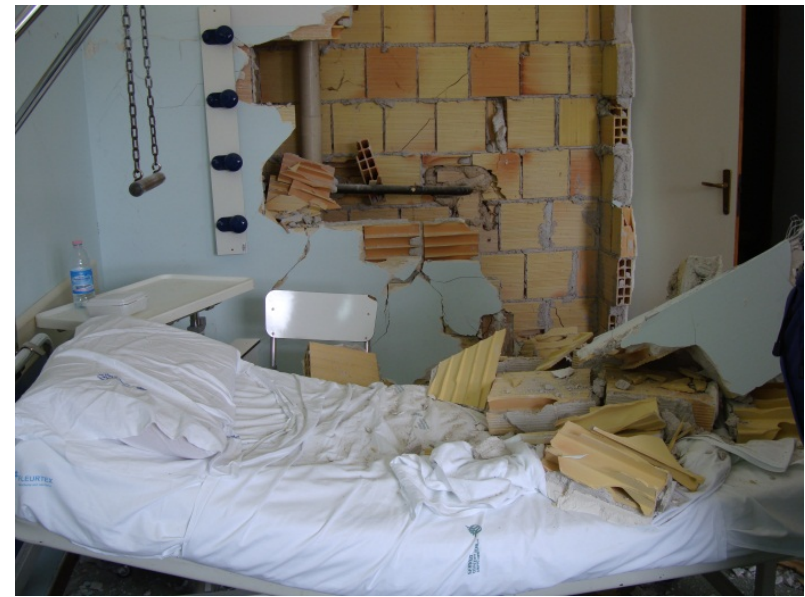

(b)

Fig. 1. Damage recorded in hollow brick partitions after 2009 L'Aquila earthquake in (a) a residential building and (b) in San Salvatore hospital.

In this paper the seismic performance of hollow brick partitions is investigated. Such partitions are built in order to be representative of the "classical" existing partitions, widespread in the European area. The seismic performance evaluation is pursued via shake table tests with increasing intensity. The shake table tests allow subjecting the partition simultaneously to interstorey relative displacements in their own plane and accelerations in the out of plane direction. 
The recorded damage states are correlated to an engineering demand parameter through the use of a damage scheme; some considerations on the hysteretic curve, the natural frequency, the damping ratio and the partition base shear are made through a complete analysis of the recorded quantities.

\section{EXPERIMENTAL FACILITIES AND TEST SET UP, SPECIMENS AND INPUT}

The shake table tests aim to investigate the seismic behaviour of hollow brick partitions. As shown in Fig. 2, the test setup consists of: (a) a shake table simulator; (b) an existing 3D steel test frame, used in a test campaign on plasterboard partitions [5, 9], able to transfer the seismic input to the partitions; (c) the specimen, i.e. hollow brick partitions.

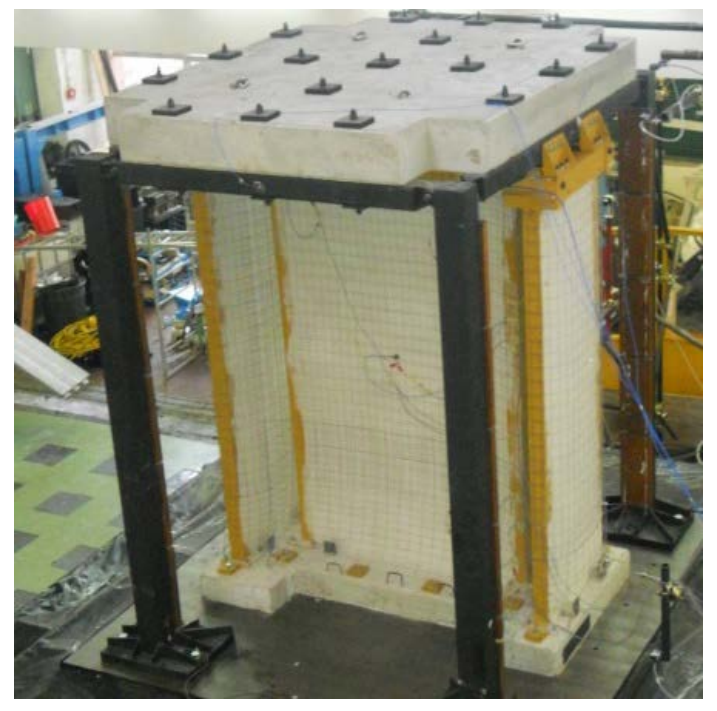

Fig. 2. Global view of the test setup.

The seismic qualification of hollow brick partitions is carried out by the earthquake simulator system available at the laboratory of the Department of Structures for Engineering and Architecture at the University of Naples Federico II. The system consists of two $3 \mathrm{~m}$ x $3 \mathrm{~m}$ square shake tables. Each table is characterized by two degrees of freedom in the two horizontal directions. The maximum payload of each shake table is $200 \mathrm{kN}$ with a frequency range of $0-50 \mathrm{~Hz}$, peak acceleration, associated to the maximum payload, equal to $1.0 \mathrm{~g}$, peak velocity equal $1 \mathrm{~m} / \mathrm{sec}$ and total displacement equal to $500 \mathrm{~mm}( \pm 250 \mathrm{~mm})$. Only one shake table is used in this experimental campaign.

The function of the existing test frame is to dynamically excite the specimen, subjecting the partitions to a wide range of interstorey drifts and accelerations. Indeed, internal partitions are architectural nonstructural components that are displacement-sensitive in their own plane and acceleration-sensitive in their out of plane direction. A steel test frame is therefore designed in order to simulate the seismic behaviour of a generic storey of a structure located in a high seismicity area [8]. In particular, it is characterized by:

- a realistic value of mass, i.e. specific mass ratio equal to $1.0 \mathrm{t} / \mathrm{m}^{2}$;

- a realistic stiffness: the interstorey displacement $d_{r}$ is assumed to be equal to 0.005 times the interstorey height, for a "frequent" (i.e. 50 years return period) earthquake typical of high seismicity areas. Indeed, the test frame is designed in order to exhibit a $0.5 \%$ interstorey drift for an earthquake characterized by $S_{D S}$ equal to $0.60 \mathrm{~g}$. Such an intensity level is representative of an earthquake with 0.24 g peak ground acceleration, i.e. an intensity level of earthquake with 50 years return period in a high seismicity zone according to the indications included in [15].

The columns of the test frame are 150x150x15 mm box sections, according to the parametric study included in [8]; each column is $2.9 \mathrm{~m}$ high. Steel horizontal beams, consisting of 120x120x15 mm cross section profiles, are connected to the columns through pin connections. At the top of the 
structure a reinforced concrete slab is placed; its plan dimensions are 2,15 m x 2,65 m and its thickness is $250 \mathrm{~mm}$. The total mass of the test frame (excluding partitions) is $5.215 \mathrm{t}$. The test frame is designed according to the Eurocodes 3 and 8 [16-18] by modal response spectrum analysis. It is considered one load combination, the seismic one, with the two orthogonal horizontal components acting simultaneously. The behaviour factor is assumed to be equal to 1 , since the test frame is designed to remain in the elastic range even if subjected to the most intense input acceleration time history. Further details on the definition of the test frame are indicated in [14].

The specimen consists of three partitions and as many steel frames surrounding them placed on an "I" shape RC slab (Fig. 3): the steel frames and the slab connect the specimen with the existing test frame and the shake table. The partitions are constituted by hollow bricks jointed and plastered with mortar; the vertical joints among the bricks are staggered.

\subsection{Test setup and specimen: definition of proper boundary conditions}

The design and the geometry of the setup are defined to simulate the realistic conditions to which a standard hollow brick partition is typically subjected.

The specimen is doubly symmetric and presents a $150 \mathrm{~cm}$ wide partition and two smaller $80 \mathrm{~cm}$ wide partitions in the orthogonal direction. The partitions are $2.6 \mathrm{~m}$ high; the connection between the specimen and the shake table is ensured by an "I" shape RC slab (Fig. 3a).

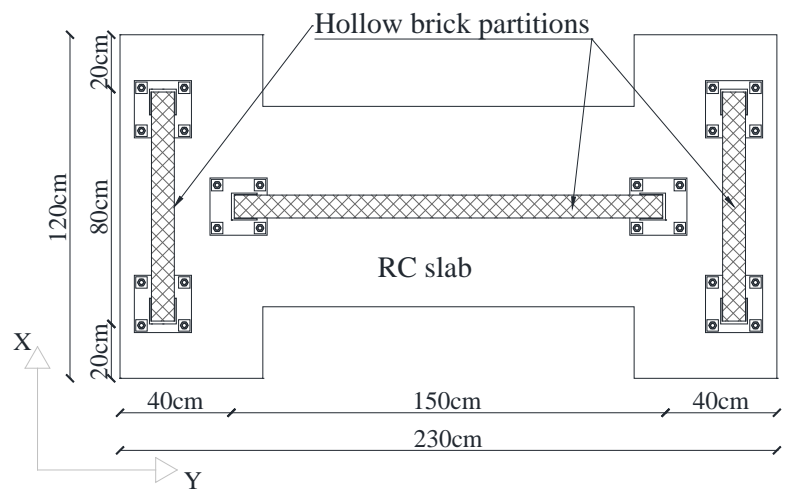

(a)

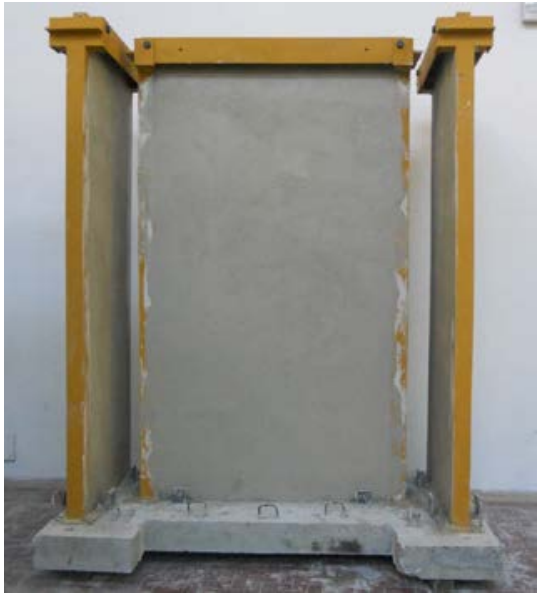

(b)

Fig. 3. Specimen: (a) plan view; (b) general view.

The walls are made with hollows bricks 250x250x80 mm connected together and plastered with mortar. A steel frame is defined around the partition (Fig. 3b) in order to connect the specimen to the existing test frame and to reproduce the partition typical conditions, in which it is disposed between two restraining orthogonal panels. The columns of the steel frame, i.e. welded 90x90x5mm "C" profiles, are hinged to the top horizontal beams. Indeed a hollow brick partition is typically placed between other two orthogonal partitions that restrain it, introducing alternatively the bricks in the orthogonal partitions. The gaps along the vertical edges of the partition, which result from this schematization, are filled with mortar to reproduce the bricks of the ideal orthogonal partitions (Fig. 4).

Due to their low lateral stiffness, it can be assumed that the steel profiles do not interfere with the partitions in resisting to the horizontal actions. The total mass of the specimen, i.e. RC slab, partitions and surrounding steel frame, is $2.24 \mathrm{t}$. 


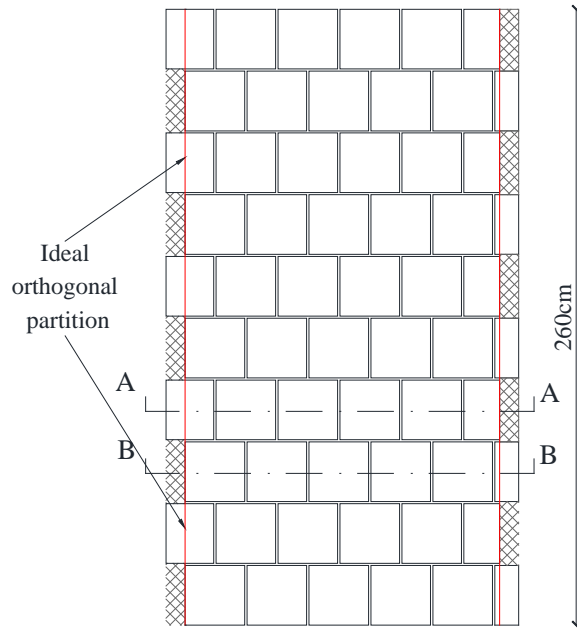

(a)
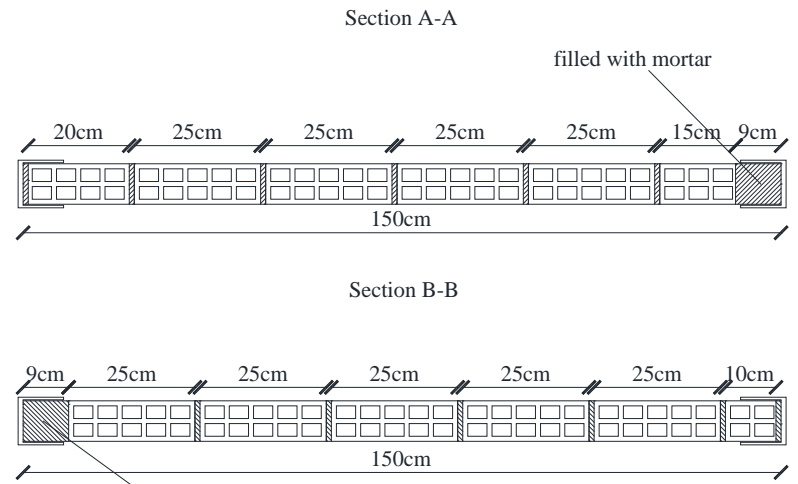

filled with mortar

(b)

Fig. 4. Cross sections of the specimen: (a) front view of the larger partition; (b) cross sections of the larger partition: gaps filled with mortar to reproduce the presence of the orthogonal partitions.

The plan layout of the panels ensures the global system to have a comparable stiffness in both orthogonal directions; indeed, two $80 \mathrm{~cm}$ wide walls are arranged orthogonally with respect to the larger, $150 \mathrm{~cm}$ wide, partition (Fig. 3a).

The width of the larger partition is determined by making a compromise between two different requirements. In particular, the width should be:

- $\quad$ sufficiently large, i.e. a width larger than $1.00 \mathrm{~m}$, in order to test a realistic partition;

- sufficiently narrow to allow the investigation of the whole damage states range of the nonstructural component up to the failure of the component (see Section 2.4).

\subsection{Instrumentation}

Accelerometers, strain gauges and displacement laser sensors are used to monitor the response of both the test frame and the specimen.

One accelerometer, placed inside the shake table, measures the input accelerations in both the directions. Seven accelerometers are also arranged in order to monitor different points of the setup, as shown in Fig. $5 b$.

The accelerometers 1, 2, 4 and 5 are installed on the top of the setup (Fig. 5a); in particular, the accelerometers 1 and 2 are placed at half height of a test frame beam oriented in $\mathrm{Y}$ and $\mathrm{X}$ direction, respectively; the accelerometers 4 and 5 are located on the beam of the frame surrounding the largest partition, in order to verify the acceleration to which the specimen is subjected; the accelerometers 3 and 7 are positioned at the base of the column of the test frame and at the base of the frame surrounding one of the small partitions, respectively; accelerometer 6 is placed in the centroid of the main partition, in order to monitor the acceleration on the partition in the out of plane direction. 


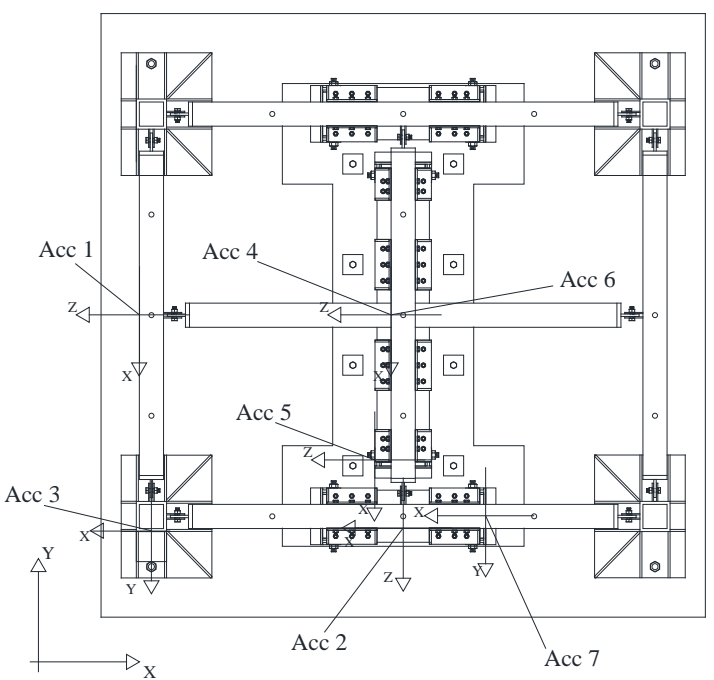

(a)

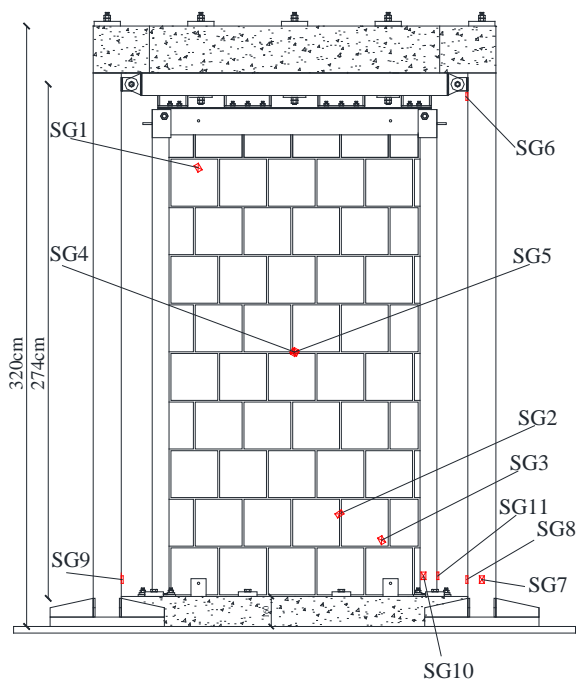

(b)

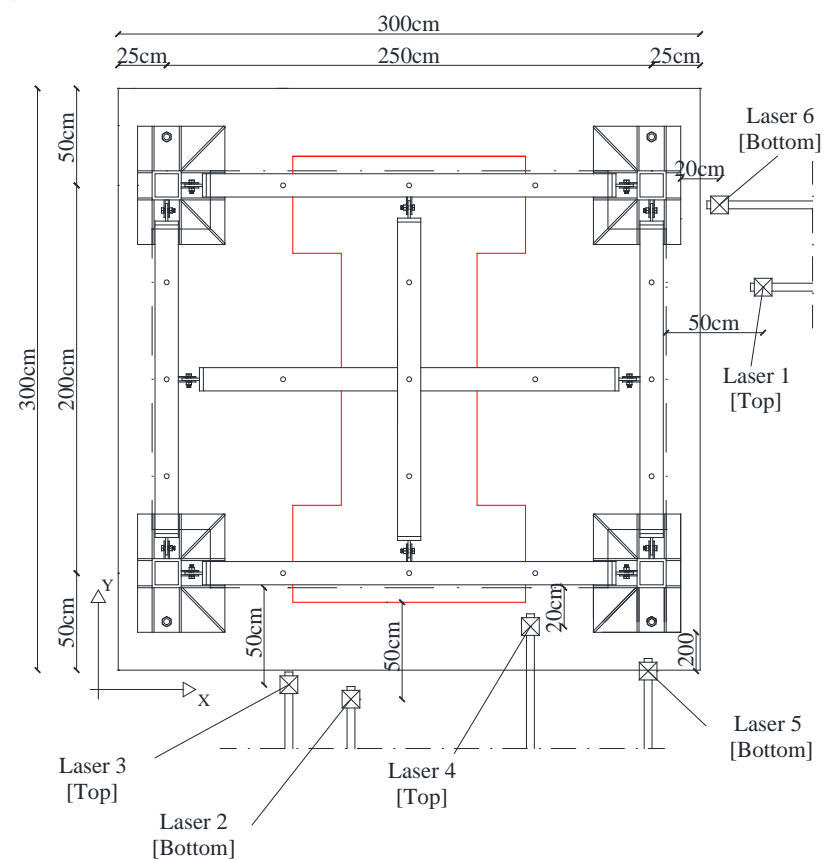

(c)

Fig. 5. Instrumentation arrangement: (a) accelerometers position; (b) strain gauges arrangement; (c) displacement laser sensors layout.

Eleven strain gauges are adopted and indicated in Fig. 5b: four strain gauges placed on the column of the test frame (SG6, SG7, SG8 and SG9); two strain gauges placed at the base of the column of the steel frame (SG10 and SG11); three diagonal strain gauges placed on the partition (SG1, SG2 and SG3), and a double strain gauge in the middle of the wall (SG4 and SG5).

Six laser-optical sensors are used to monitor the displacements in specific points of the test setup. Three lasers are placed at steel base plate mid-height (base plate that connects column to shaking table); the other three ones are placed halfway on the concrete slab (Fig. 5c shows the laser arrangement).

\subsection{Input and testing protocol}

The input to the table is obtained from time histories representative of a target ground motion and acting simultaneously along the two horizontal directions; the time histories are artificially defined to match the required response spectrum (RRS) provided by the AC156 code "Acceptance criteria for seismic qualification testing of non-structural components" [19]. The testing protocols included 
in FEMA 461 [20] and in Retamales et al. [21] are also considered. The AC156 protocol is preferred since the accelerogram provided by AC156 is better reproduced by the shake table facility used in this study. Moreover, this choice allows a straightforward comparison with previous studies that adopted the same testing protocol [8].

According to ICBO [19], the RRS is obtained as a function of the spectral acceleration at short periods, i.e. $\mathrm{S}_{\mathrm{DS}} . \mathrm{S}_{\mathrm{DS}}$ is the parameter characterizing the ground motion. For horizontal design-basis earthquake shaking, the International Building Code [22] defines the short period design-basis earthquake acceleration as follows:

$$
S_{D S}=\frac{2}{3} \cdot F_{A} \cdot S_{S}
$$

where $\mathrm{F}_{\mathrm{A}}$ is a site soil coefficient and $\mathrm{S}_{\mathrm{S}}$ is the mapped maximum considered earthquake (MCE) spectral acceleration at short periods.

Two artificial acceleration time histories are defined so as their response spectra, i.e. test response spectra, envelope the target spectrum over the frequency range from 1.3 to $33.3 \mathrm{~Hz}$. The test response spectrum ordinates do not have to be lower than 0.9 times RRS and larger than 1.3 times RRS (according to EC8 [23] and AC156 rules respectively). The low frequency content is removed from the accelerograms in order to not exceed the displacement and velocity limitations of the earthquake simulator. The damping ratio for the evaluation of the response spectra is set equal to $5 \%$. Further details are given in [5].

In Fig. 6 the obtained time histories for the $\mathrm{X}$ and $\mathrm{Y}$ directions in terms of acceleration, velocity and displacement, their elastic response acceleration spectra, the RRS corresponding to $\mathrm{S}_{\mathrm{DS}}$ equal to $1.50 \mathrm{~g}$ and the RRS scaled to $90 \%$ and $130 \%$ are shown. 

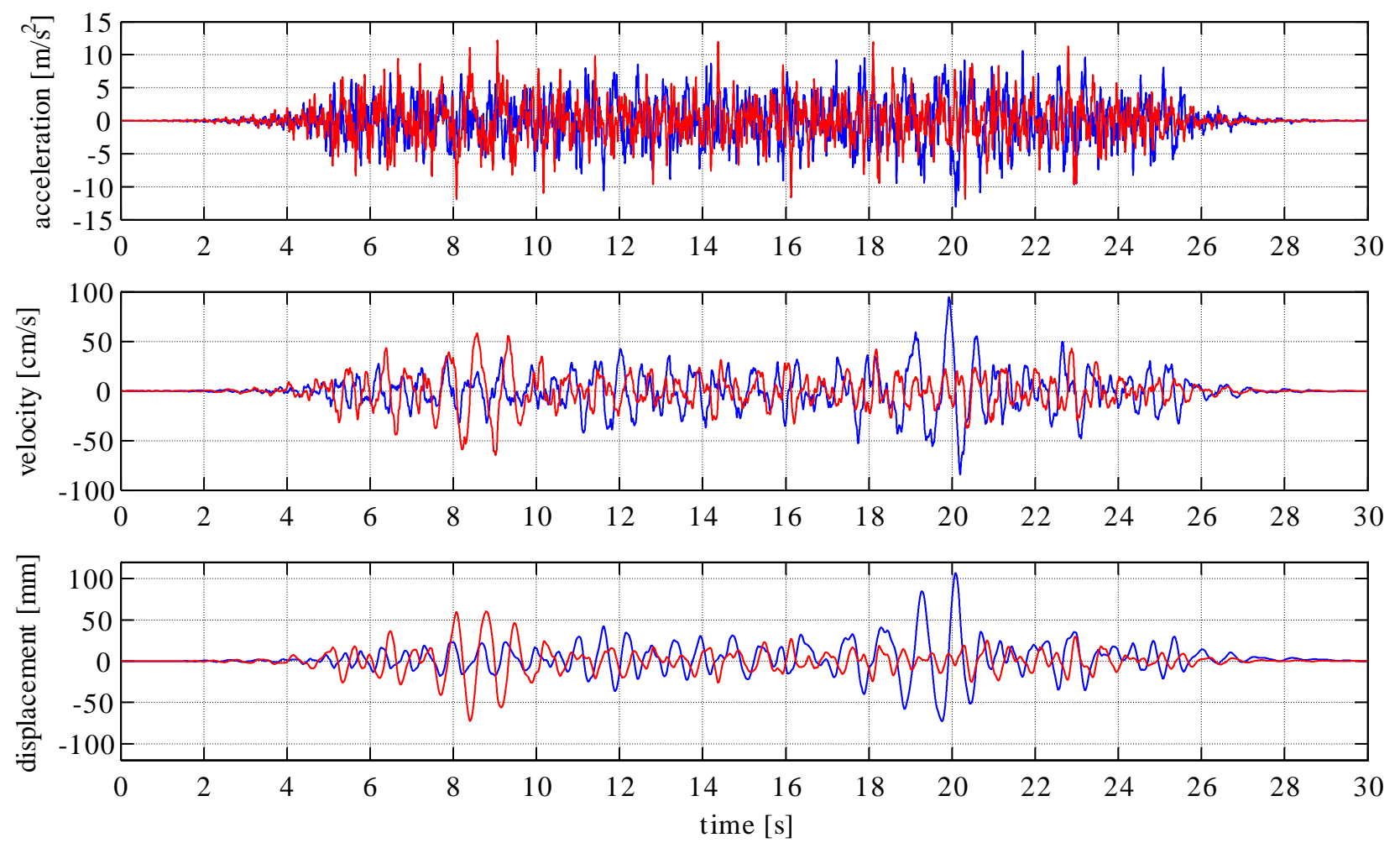

(a)

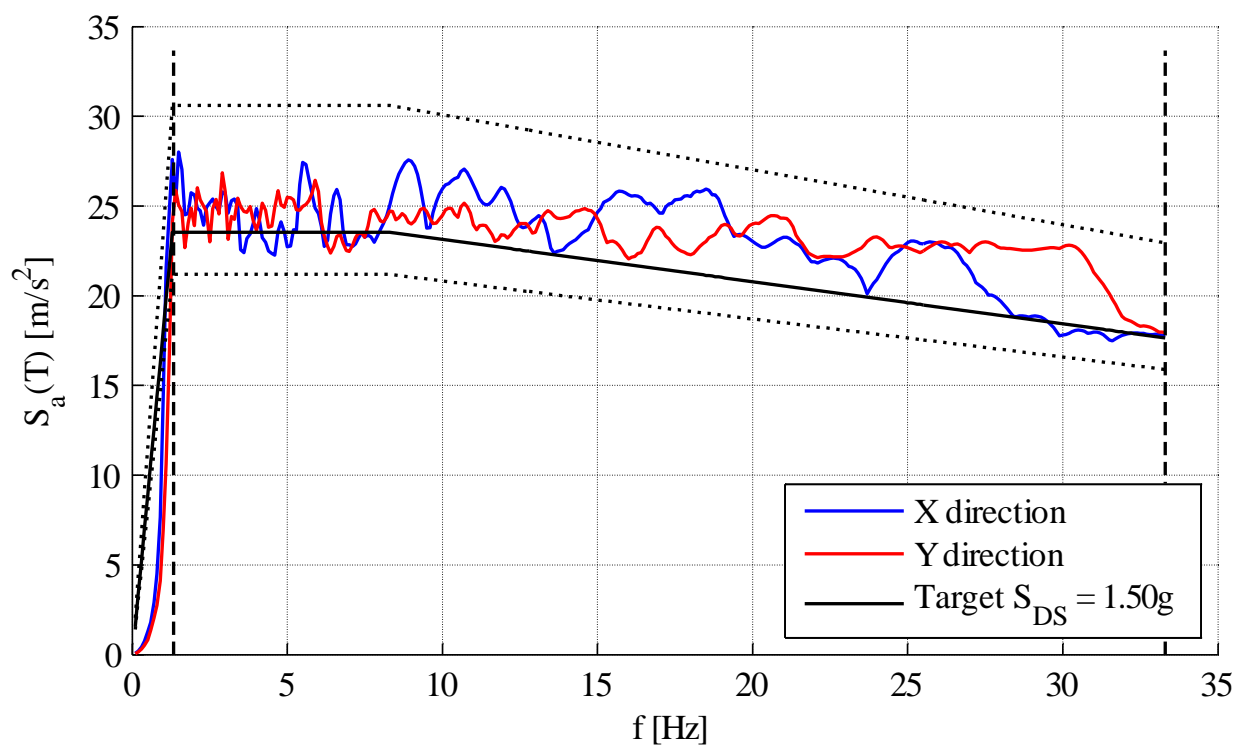

(b)

Fig. 6. Input time histories and spectra for $S_{D S}$ equal to 1.50 g: (a) acceleration, velocity and displacement time-history - X direction (blue) and Y direction (red); (b) input accelerogram spectra, RRS (bold line), upper and lower limits (dashed line), matching frequency range (vertical dashed line).

The input levels for the test campaign range from $S_{D S}=0.30 \mathrm{~g}$ to $S_{D S}=1.50 \mathrm{~g}$ in order to generalize the execution of the test and to make it representative of a large range of real earthquakes. Particularly, five bidirectional tests with different intensity values are defined (Table 1). 
Table 1. $\mathrm{S}_{\mathrm{DS}}$ and corresponding peak ground acceleration $\left(\mathrm{a}_{\mathrm{g}}\right)$ values for the five input test levels.

\begin{tabular}{ccc}
\hline Test no. & $S_{D S}$ & $a_{g}$ \\
\hline$[-]$ & {$[\mathrm{g}]$} & {$[\mathrm{g}]$} \\
\hline 1 & 0.30 & 0.12 \\
\hline 2 & 0.60 & 0.24 \\
\hline 3 & 0.90 & 0.36 \\
\hline 4 & 1.20 & 0.48 \\
\hline 5 & 1.50 & 0.60 \\
\hline
\end{tabular}

Even if AC156 is intended for acceleration-sensitive components, e.g. ceilings, the input motion is defined according to such a procedure for the following reasons:

- internal partitions are mainly displacement sensitive components; however, out of plane acceleration can cause the damage/collapse of these components;

- the use of a flexible test frame, subjected to the defined input motions, allows investigating the behaviour of the tested component at different levels of relative displacement demands.

\subsection{Definition of the partition dimensions: preliminary "blind" prediction}

As explained in Section 2.1, the dimensions of the largest partition are defined in order to accomplish two main goals: to test a realistic partition and to investigate all the different damage states, i.e. from minor damage to collapse, of the specimen during the different tests. For the latter motivation partition sizes are chosen so as to activate failure mechanisms during the programmed tests.

The partition width should be less than one meter according to the typical amount of partitions contained in the floor area of the test setup. However, a $1.50 \mathrm{~m}$ wide partition is chosen in order to test a more realistic specimen.

Preliminary analyses are conducted to evaluate the capacity of the chosen partition, in order to define the partition as large as possible and, simultaneously, bring the partition to collapse at least at the highest intensity level.

The in plane capacity is estimated making a non-linear dynamic analysis, using the acceleration time-histories defined in Section 2.3, through the OpenSees program [24]. In particular, the system is modelled as a SDOF system having a force-displacement relationship obtained considering an elastic-linear behaviour for the steel elements and the partition in plane behaviour is reproduced by the model proposed by Panagiotakos and Fardis [25]. The F- $\delta$ relationship presents a capping point defined by a displacement equal to $6.5 \mathrm{~mm}$ and a force equal to $95.5 \mathrm{kN}$. Non-linear dynamic analyses (omitted for the sake of brevity) show the collapse of the partition in Y-direction at the test no. 5.

Concerning the out of plane behaviour of masonry walls, different research studies were conducted in the past years, both on unreinforced masonry [26] and on FRP strengthened walls [27]. The out of plane capacity is evaluated in terms of the average acceleration ( $\mathrm{a}_{\text {collapse}}$ ) in the out of plane direction that causes the collapse of the specimen. The collapse acceleration, evaluated upon the out of plane load that causes the failure according to different formulations available in literature, is reported in Table 2. 
Table 2. Average acceleration ( $\mathrm{a}_{\text {collapse }}$ ) in the out of plane direction that causes the collapse of the specimen according to different formulations.

\begin{tabular}{|l|c|}
\hline \multicolumn{1}{|c|}{ Method } & $\mathrm{a}_{\text {collapse }}$ \\
\cline { 2 - 2 } & [g] \\
\hline Angel et al. [28] & 1.89 \\
\hline Cohen and Laing [29] & 4.86 \\
\hline Dawe and Seah [30] & 4.80 \\
\hline Eurocode 6 [31] & 3.38 \\
\hline Flanagan and Bennett [32] & 4.35 \\
\hline Garbin [33] & 1.96 \\
\hline Moghaddam and Goudarzi [34] & 2.74 \\
\hline
\end{tabular}

The formulations suggested by Dawe and Seah [30] and Flanagan and Bennett [32] consider that the partition is able to arch itself along both vertical and horizontal directions, depending on its boundary conditions. According to the limited width of the tested specimen, they are considered to be the most reliable. Comparing the collapse acceleration in the out of plane direction with the highest spectral acceleration for the test highest intensity level, i.e. $2.4 \mathrm{~g}$, the collapse due to an out of plane action is not expected during the tests.

\section{RESULTS AND DISCUSSION}

\subsection{Dynamic identification}

Before the execution of the test campaign, low-intensity random excitations are selected as input motions for the bare test frame in order to evaluate the natural frequency of the test frame in both the horizontal directions. The transfer curve method is applied between the base and the top acceleration time histories (Fig. 7). The bare frame natural frequencies, denoted by the peak in the transfer curves, in X and Y directions (see Fig. 5) are $3.83 \mathrm{~Hz}$ and $4.04 \mathrm{~Hz}$, respectively. After the specimen is installed within the test frame and before executing the five shake table runs, a random vibration is also applied in both the horizontal directions in order to measure the influence of the specimen on the natural frequency of the test setup. As shown in Fig. 7, the "infilled" natural frequencies of the test setup significantly increase up to $8.01 \mathrm{~Hz}$ and $7.62 \mathrm{~Hz}$ in X and Y directions. This confirms the large in plane stiffness of the specimen that significantly influences the dynamic properties of the test setup.

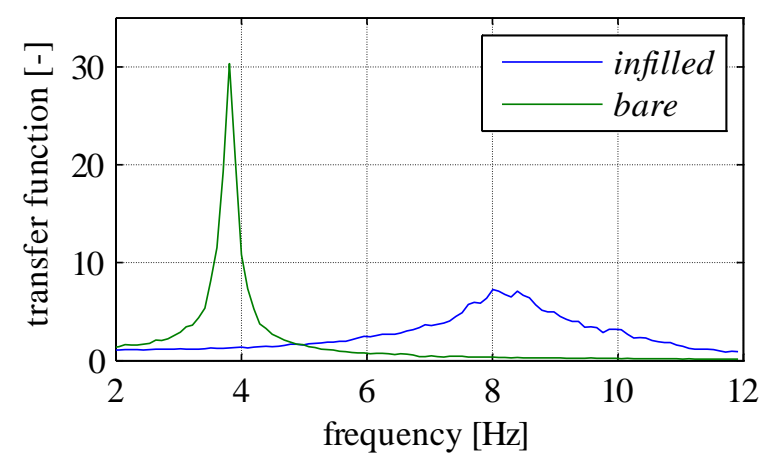

(a)

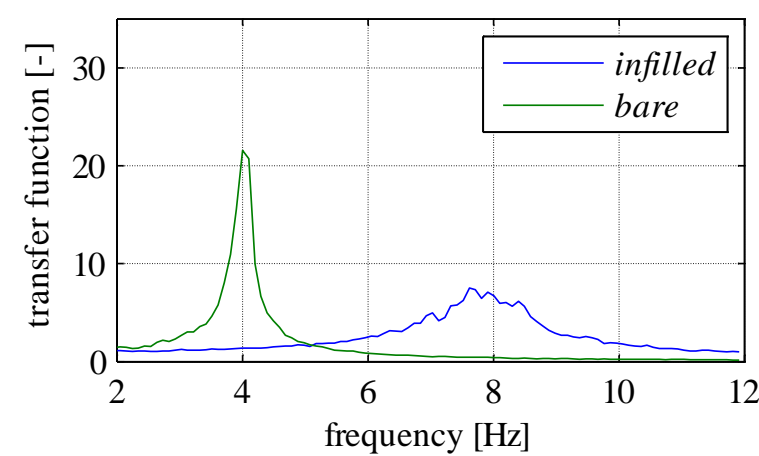

(b)

Fig. 7. Transfer functions between base and top acceleration time histories for a low-intensity random vibration applied to both bare and infilled test setups (a) in X direction and (b) in Y direction. 


\subsection{Results summary}

Using the selected drive motions, five bidirectional shaking tests are performed. In Table 3 the maximum recorded values of acceleration on the roof of the test frame and the maximum recorded values of relative displacement are listed. The relative displacement is evaluated using the laser recordings at the top and at the base of the test frame. The acceleration values are measured by the accelerometers placed on the test frame top horizontal beams. Dynamic amplifications in the test setup lead to acceleration values larger than $2.0 \mathrm{~g}$ on the roof in both $\mathrm{X}$ and $\mathrm{Y}$ directions. Due to a limitation imposed by the shake table facility, in the test no. 5 the input acceleration intensity value in the $\mathrm{X}$ direction is the same as in the test no. 4. This issue has not affected the Y direction, i.e. the largest partition direction, where the system reached higher accelerations in the last test shaking. In order to analyse the partition behaviour and its contribution to the global behaviour of the test setup, the top acceleration, representative of the total inertia force, is plotted versus the relative displacement for different intensity levels (Fig. 8). A dotted line denotes the behaviour of the bare test frame based on its natural frequency and assuming to be in absence of damping.

Table 3. Maximum recorded accelerations at the test frame roof and maximum recorded relative displacements in $\mathrm{X}$ and $\mathrm{Y}$ directions for the different test runs.

\begin{tabular}{ccccccc}
\hline test no. & Direction & $\mathbf{1}$ & $\mathbf{2}$ & $\mathbf{3}$ & $\mathbf{4}$ & $\mathbf{5}$ \\
\hline top acceleration [g] & $\mathrm{X}$ & 0.58 & 1.11 & 1.52 & 2.10 & 1.99 \\
relative displacement [mm] & & 3.67 & 9.71 & 18.22 & 27.05 & 27.51 \\
top acceleration [g] & & 0.67 & 1.14 & 1.52 & 1.95 & 2.39 \\
relative displacement [mm] & $\mathrm{Y}$ & 3.39 & 6.14 & 11.40 & 18.08 & 26.54 \\
\hline
\end{tabular}

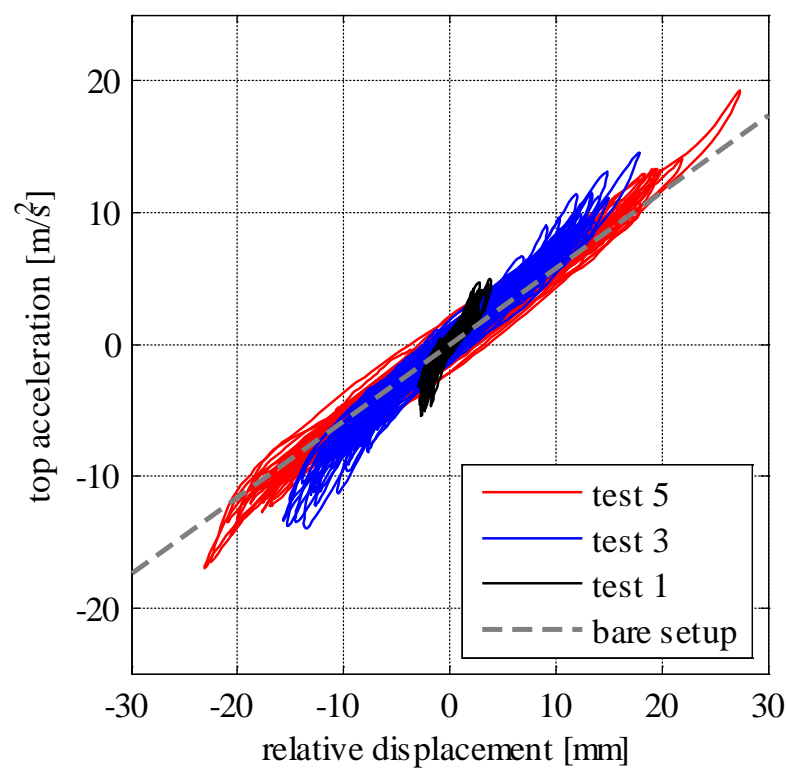

(a)

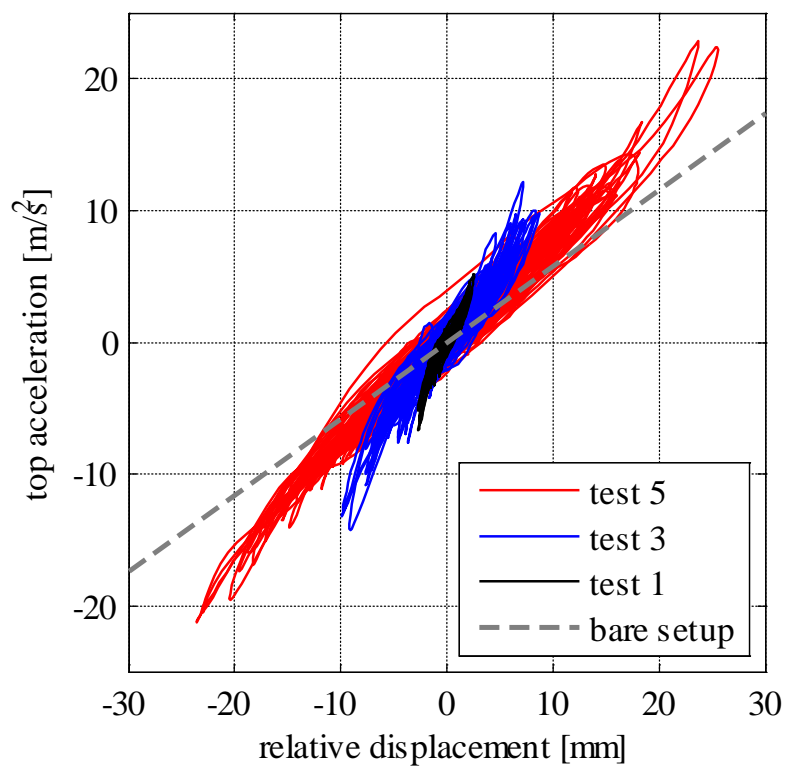

(b)

Fig. 8. Top acceleration vs relative displacement plot for different seismic tests in (a) $X$ direction and (b) $Y$ direction.

From the analysis of the so-obtained hysteretic curves it can be noted that:

- a significant interaction between the partitions and the hosting structure is exhibited during the first test; during the fifth test, the hysteretic behaviour is very close to the bare frame response;

- the secant stiffness, evaluated at the maximum displacement of each test, decreases as the relative displacement increases; 
- the negligible influence of the partitions during the fifth test denotes the collapse of the specimen.

\subsection{Damage description}

In this study three damage states are considered for the seismic response definition of the partitions and in particular:

- $\quad$ DS1 $\rightarrow$ Minor damage state;

- DS2 $\rightarrow$ Moderate damage state;

- $\quad$ DS3 $\rightarrow$ Major damage state.

Minor damage state achievement implies the need of repairing the specimen, in order to restore its original condition, e.g. plaster replacing. Moderate damage state achievement, instead, implies that the nonstructural component is damaged so that it must be partially removed and replaced. Major damage state implies that the damage level is such that the partition needs to be totally replaced or the life safety is not ensured. The damage state definitions and their repercussions are indicated in Table 4, based upon the damage state definition given by Taghavi and Miranda in [3]. In particular the correlation between each damage state and the loss is given in terms of [20]: (a) life loss (deaths), (b) direct economic loss due to the repair or replacement of the NSC (damage) and (c) occupancy or service loss (downtime). Furthermore after each test, damage is observed inspecting the specimen components and consequently an appropriate damage table is compiled (Table 4). The level of damage required to overcome a limit state for each damage typology is defined. This process is very useful in order to define the fragility curves for this nonstructural component typology. 
Table 4. Damage state definitions and their repercussions for hollow brick partitions

\begin{tabular}{|c|c|c|c|}
\hline Test ID & & ASSESSMENT & JS1 \\
\hline COMPONENT & $\begin{array}{l}\text { DAMAGE } \\
\text { STATE } \\
\end{array}$ & $\begin{array}{c}\text { TYPE OF } \\
\text { CONSEQUENCE }\end{array}$ & INFORMATION \\
\hline \multirow{15}{*}{$\begin{array}{l}\text { Hollow brick } \\
\text { partition }\end{array}$} & \multirow{5}{*}{$\begin{array}{l}\text { Damage state } 1 \text { : } \\
\text { hairline cracks } \\
\text { (width }<0.3 \mathrm{~cm}) \text { in } \\
\text { mortar and wall } \\
\quad \text { finishes }\end{array}$} & Repair actions & $\begin{array}{l}\text { The wall needs some minor repairs of exterior } \\
\text { finishes }\end{array}$ \\
\hline & & Damage consequences & $\begin{array}{c}\text { It has no effect on the performance of other } \\
\text { components and the building can be used } \\
\text { immediately }\end{array}$ \\
\hline & & Functionality of bldg. & Fully functional \\
\hline & & Life hazard & None \\
\hline & & $\begin{array}{l}\text { Component loss of } \\
\text { function }\end{array}$ & None \\
\hline & \multirow{5}{*}{$\begin{array}{l}\text { Damage state } 2 \text { : } \\
\text { severe cracks } \\
\text { (width }>0.3 \mathrm{~mm} \text { ) in } \\
\text { wall and spalling } \\
\text { of pieces of brick }\end{array}$} & Repair actions & $\begin{array}{l}\text { Depending on the damage extent, some parts of } \\
\text { the wall may need demolition and } \\
\text { reconstruction. Also the damaged area needs } \\
\text { repair of the exterior plaster and painting }\end{array}$ \\
\hline & & Damage consequences & $\begin{array}{l}\text { The functionality of the rooms adjacent to the } \\
\text { damaged wall may be interrupted until the wall } \\
\text { gets repaired. If there are some small sensitive } \\
\text { electrical and mechanical devices on the wall, } \\
\text { they may not function and need repair }\end{array}$ \\
\hline & & Functionality of bldg. & Partially functional \\
\hline & & Life hazard & Small \\
\hline & & $\begin{array}{l}\text { Component loss of } \\
\text { function }\end{array}$ & Moderate \\
\hline & \multirow{5}{*}{$\begin{array}{l}\text { Damage state } 3: \\
\text { total failure of the } \\
\text { wall }\end{array}$} & Repair actions & $\begin{array}{l}\text { The damaged area must be completely } \\
\text { demolished and a new wall must be } \\
\text { reconstructed. }\end{array}$ \\
\hline & & Damage consequences & $\begin{array}{l}\text { The damaged wall must be demolished and } \\
\text { reconstructed before the adjacent rooms can } \\
\text { regularly function. Electrical systems, such as } \\
\text { plugs and wiring, and mechanical systems, such } \\
\text { as piping, may break or not work. }\end{array}$ \\
\hline & & Functionality of bldg. & Partially functional \\
\hline & & Life hazard & High \\
\hline & & $\begin{array}{l}\text { Component loss of } \\
\text { function }\end{array}$ & High \\
\hline
\end{tabular}

Bidirectional tests show a slight damage already up to $0.35 \%$ drift in $\mathrm{X}$ direction and $0.20 \%$ in $\mathrm{Y}$ direction. The damage level increases according to the shaking test intensity and the following damages are noticed:

- cracks along the perimeter of the specimen due to the partitions slip from the surrounding frame in test no. 2;

- fall of plaster and pieces of brick from the top of the specimen from test no. 3 with increasing intensity as the demand increases;

- horizontal cracks, wider than $0.3 \mathrm{~mm}$, in the lower part of the walls in test no. 3 (Fig. 9a); 
- wide sliding cracks in mortar, crushing of mortar at the corner of the specimen and collapse of a brick in the top of the partition in test no. 4 (Fig. 9b and Fig. 9c);

- deep extended horizontal cracks in the mortar in the lower part of the walls, that let the part above the crack moves as a rigid block with a rocking behaviour with respect to the surrounding frame in test no. 5 (Fig. 9d and Fig. 10a). At this damage level, the specimen does not offer any resistance against lateral displacements since it rigidly moves and rotates within the surrounding frame that restraints it in the out of plane direction.

It should be noted that during the tests the specimen is wrapped with a metallic grid without any connection, only for safety purposes. The grid does not give any contribution to the specimen in resisting to the lateral forces.

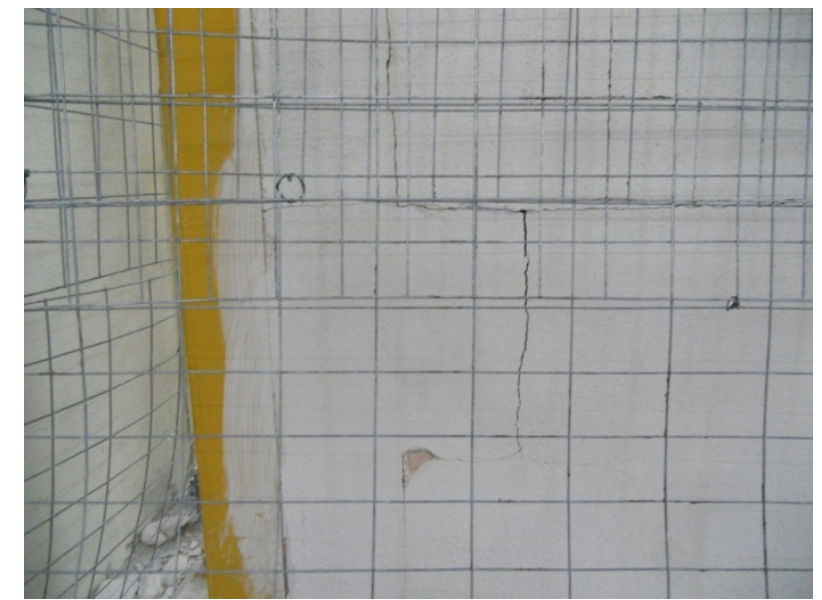

(a)

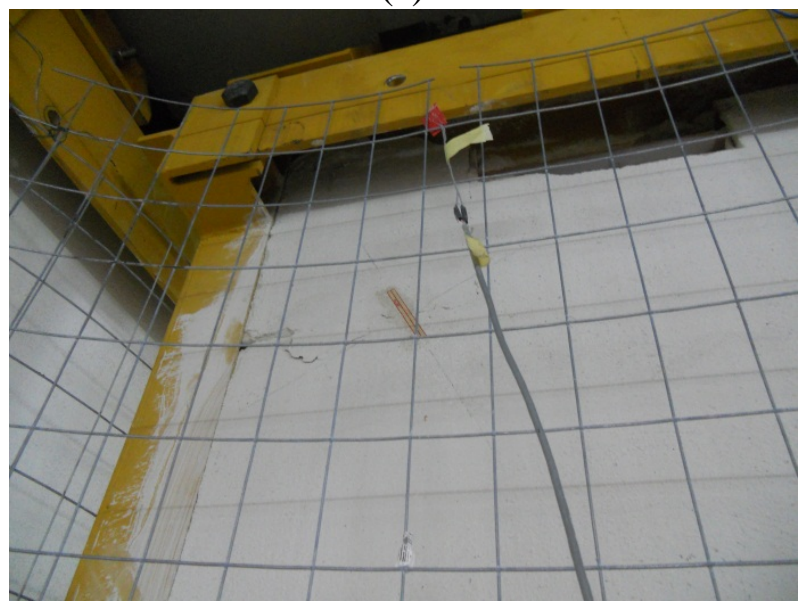

(c)

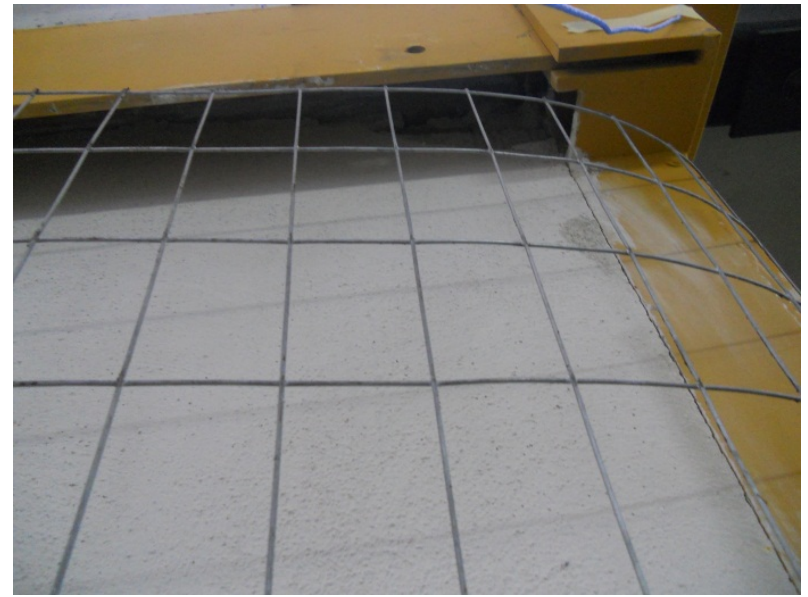

(b)

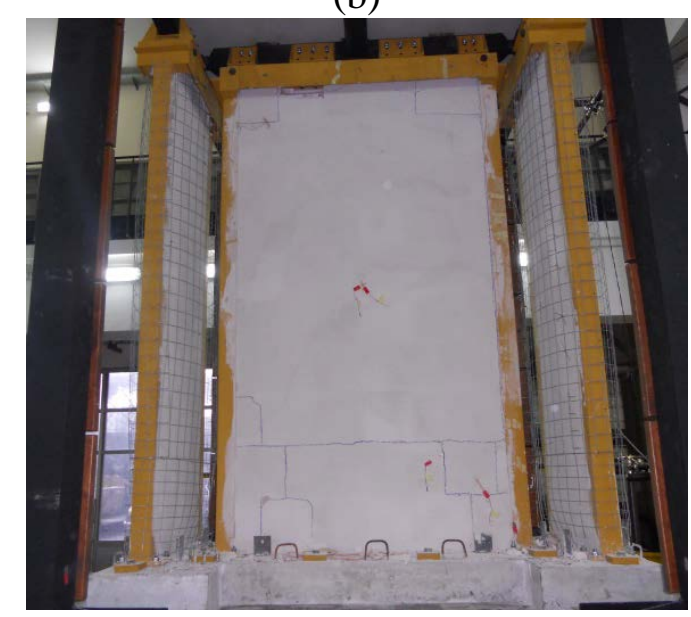

(d)

Fig. 9. Recorded damage after different shaking tests: (a) wide sliding cracks in mortar in the joints between the bricks; (b) crushing of mortar at the corner; (c) collapse of a brick in the top of the partition; (d) deep extended horizontal cracks in mortar in the lower part of the wall.

The occurred damage is mostly related to the in-plane behaviour of the partition. Failure in the out of plane direction is not observed throughout the different performed tests, confirming the outcome of the blind prediction described in Section 2.4. However, it should be noted that the specimen is tested assuming a perfect restraint, given by vertical steel $C$ elements, along the vertical edges in the out-plane direction; such a restraint simulates an excellent connection of the partition with the orthogonal walls.

In Fig. 10 the recorded damages after the last test are shown, both in the "large" partition and in the "small" one. The behaviour of the specimen is investigated considering that the elements that restrain it along the vertical edges remain undamaged during the shakings, in order to assess the fragility of the component without considering any interaction with the boundary elements. Indeed 
the steel surrounding frame remains undamaged during the different shakings. Obviously, in case the interaction between the partitions and the restraining elements had been considered, a larger fragility of the component would have been recorded.

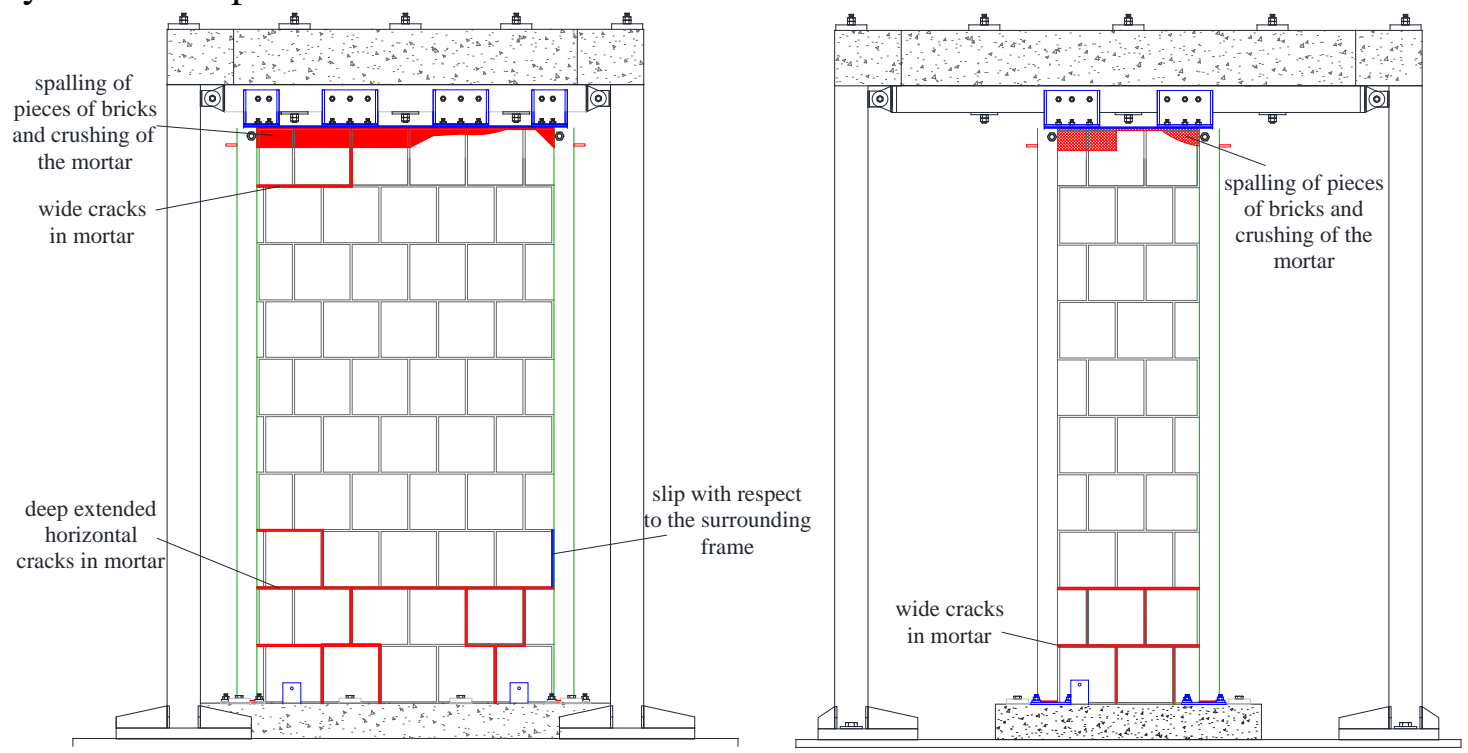

Fig. 10. Final damage state at the end of the seismic tests in the largest partition and in the smallest partitions.

A correlation between EDP (Engineering Demand Parameter), i.e. interstorey drift, and the DS (Damage State) is also defined (Table 5). Damage State 1 is attained in test no. 2 due to the need of restoring the cracked plaster along the perimeter of the wall; Damage State 2 is attained in test no. 3 , due to the formation of cracks wider than $0.3 \mathrm{~mm}$ and the need of partially replacing the partition; finally Damage State 3 is attained for an interstorey drift close to $1 \%$ in the three specimens, due to the significant damage and the consequent need of replacing the whole partition. It should be noted that the partition in Y-direction starts exhibiting significant damage for interstorey drifts smaller than the $0.5 \%$ drift limitation included in Eurocode 8.

The correlation between the damage states and the engineering demand parameters is based upon the assumption that the damage occurs at the maximum engineering demand parameter that the specimen experiences during a single test.

Table 5. Interstorey drifts and damage states in $\mathrm{X}$ and $\mathrm{Y}$ directions for the different tests.

\begin{tabular}{ccccccc}
\hline test no. & Direction & $\mathbf{1}$ & $\mathbf{2}$ & $\mathbf{3}$ & $\mathbf{4}$ & $\mathbf{5}$ \\
\hline drift [\%] & \multirow{2}{*}{$\mathrm{X}$} & 0.13 & 0.36 & 0.67 & 0.99 & 1.01 \\
Damage State & & DS0 & DS1 & DS2 & DS3 & DS3 \\
drift [\%] & & 0.12 & 0.21 & 0.34 & 0.66 & 0.97 \\
Damage State & $\mathrm{Y}$ & DS0 & DS1 & DS2 & DS2 & DS3 \\
\hline
\end{tabular}

This research study is mostly related to the experimental investigation of the seismic behaviour of brick internal partitions. Further studies will be conducted on numerical simulations, considering different refined models, such as [35-37].

\subsection{Frequency and damping evaluation}

The presence of infill systems strongly influences the lateral stiffness of the portion of the structure in which they are inserted [25], and may also affect the regularity of the structural system [38-41]. In Section 3.1 a standard technique for the evaluation of the natural frequency of the test setup allows estimating the influence of the partitions on the natural frequency of the system. In the following, instead, the change of the natural frequency during the seismic tests is investigated in order to correlate the damage to the dynamic characteristics of the specimen. 
The transfer function, estimated as the ratio between the top and the base acceleration in the frequency domain, is evaluated with respect to the time histories recorded during the different seismic tests. This method allows following the change of the natural frequency during the tests, as shown (TC values) in Fig. 11a (setup X direction) and Fig. 11b (setup Y direction).

The procedure proposed by Hashemi and Mosalam [42], which allows evaluating the average values of stiffness $k$ and damping coefficient $b$ from the dynamic equilibrium, is also implemented. This procedure consists in evaluating the values of stiffness $k$ and damping coefficient $b$ of an equivalent single degree of freedom system that minimize the error in evaluating the dynamic equilibrium equation for each time instant. Based on the "average" stiffness, the natural frequencies are evaluated and plotted (H\&M values) in Fig. 11a (setup X direction) and Fig. 11b (setup Y direction) for the different tests.

Assuming dissipation exclusively viscous, the damping ratio $\xi$ is proportional to the ratio between the dissipated energy per cycle, $\mathrm{W}_{\mathrm{D}}$ (area enclosed within each hysteresis cycle), and the elastic energy $E$ [43] as follows:

$$
\xi=\frac{W_{D}}{4 \pi E}
$$

Each hysteresis cycle of a single test is isolated to calculate its area, i.e. the dissipated energy $W_{D}$. This procedure provides as much damping values as the number of hysteresis cycles in each test. In Fig. 11c (setup $\mathrm{X}$ direction) and Fig. 11d (setup $\mathrm{Y}$ direction) the median value of damping coefficient is plotted for each test.

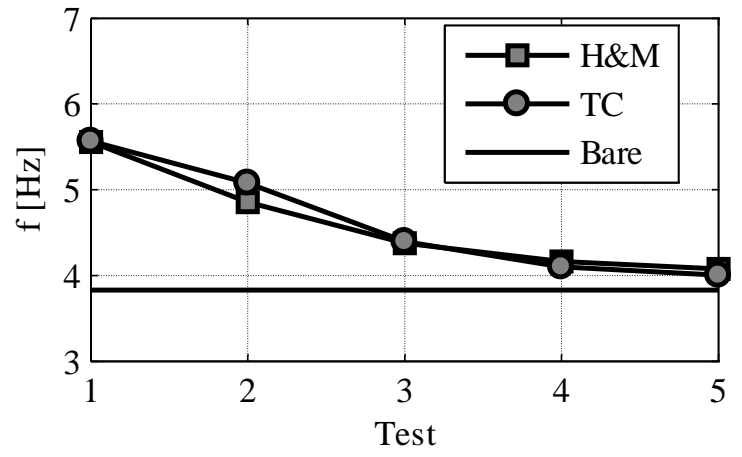

(a)

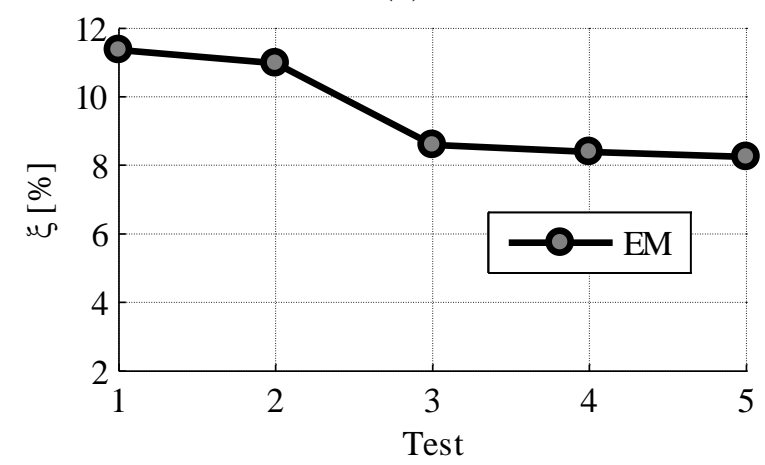

(c)

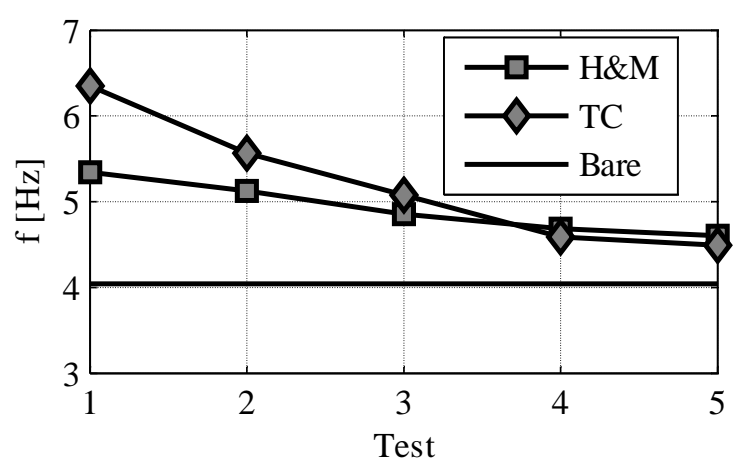

(b)

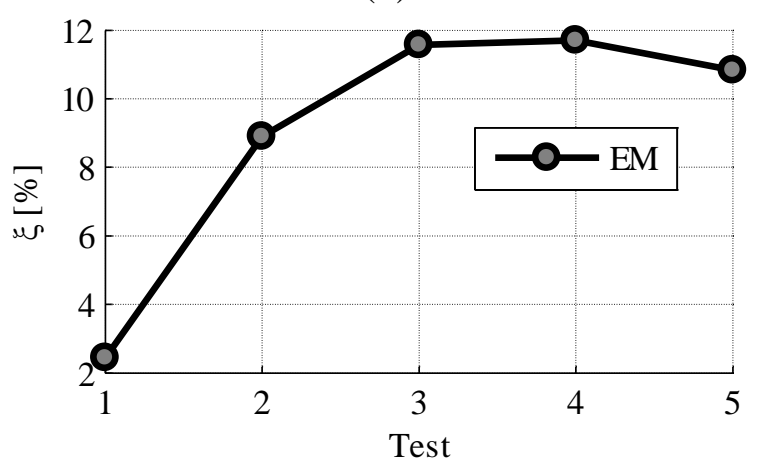

(d)

Fig. 11. Test frame natural frequency evaluation according to the Transfer Curve method (TC) and to the Hashemi and Mosalam (H\&M) procedure [42] and compared to the bare frame natural frequency (Bare) for the different seismic tests in (a) $\mathrm{X}$ and (b) $\mathrm{Y}$ directions; damping ratio evaluation according to the Energetic Method (EM) for the different seismic tests in (c) $\mathrm{X}$ and (d) Y directions.

The trend of both the natural frequency and the damping ratio confirms the recorded damage.

Natural frequency shows a great reduction during the first three tests due to the damage sustained by the specimen during the first tests and the consequent decrease of the lateral stiffness. Subsequently natural frequency values converge towards the bare frame natural frequency. 
Similarly, from test no. 1 to test no. 3 , in the $\mathrm{Y}$ direction, an increase in the damping ratio is exhibited, essentially due to the wall progressive damaging, while in the $\mathrm{X}$ direction the damping is almost constant for the different tests. The damping trends confirm that the two walls in the $\mathrm{X}$ direction start damaging before the one in the $\mathrm{Y}$ direction, since they are subjected to larger interstorey drifts (Table 3). However, it should be underlined that the estimation of the damping ratio is performed assuming that the specimen exhibits a linear elastic behaviour during each of the different tests.

In order to evaluate the natural frequency change during each single test the short time Fourier transform method [44] is implemented. In particular, for every 1 second spaced time step $t$, a 7 seconds time window centred in $t$ is considered. The transfer curve method is applied for each of the time windows, defining a transfer function for each $t$. In Fig. 12 for each considered time $t$, the transfer function is plotted in the frequency domain, defining a 3D plot. The change in the peak of the transfer function over the time allows following the reduction of the natural frequency of the setup.

In both $\mathrm{X}$ and $\mathrm{Y}$ directions the natural frequency reduction is visible, especially for the first tests. For instance, in test no. 2 in $\mathrm{Y}$ direction the natural frequency passes from about $6.5 \mathrm{~Hz}$ at the beginning of the test to about $5.5 \mathrm{~Hz}$ at the end of the test (Fig. 12). These diagrams confirm the results reported in Fig. 11.
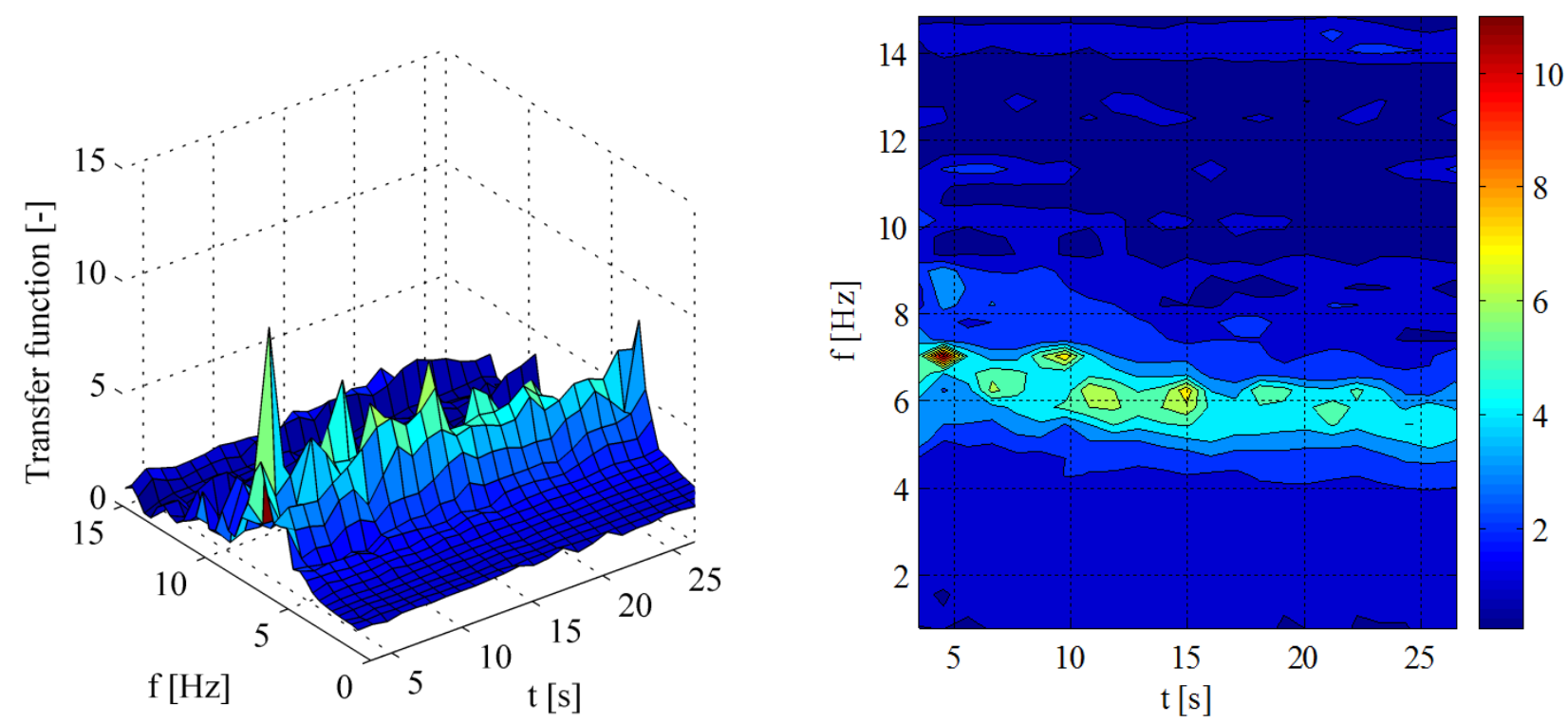

Fig. 12. Transfer function for 7 seconds time windows for different time instants corresponding to test $n .2$ in Y direction: (a) 3D view; (b) contour view.

\subsection{Base shear distribution}

Through the analysis of the hysteretic curves (Fig. 8) the base shear distribution between the partitions and the test frame is evaluated. The force adsorbed by the partitions is simply evaluated as the difference between the maximum inertia force and the force acting on the test frame; the latter force is calculated upon the natural frequency of the test frame and the reached displacement. The result is also validated using the strain gauge placed at the column base of the test frame.

In Fig. 13 the base shear distribution between partitions and test frames in every test, in X (a) and Y (b) directions, is shown. It can be seen that the test frame adsorbs an increasing shear ratio with respect to the partitions, due to the progressive damage in the specimen. After test no. 4, just a minimum residual contribution of the partitions is exhibited. The shear demand on the partitions passes from a value of approximately $60 \%$ (test no. 1) to the $15 \%$ of the total base shear (test no. 5). 


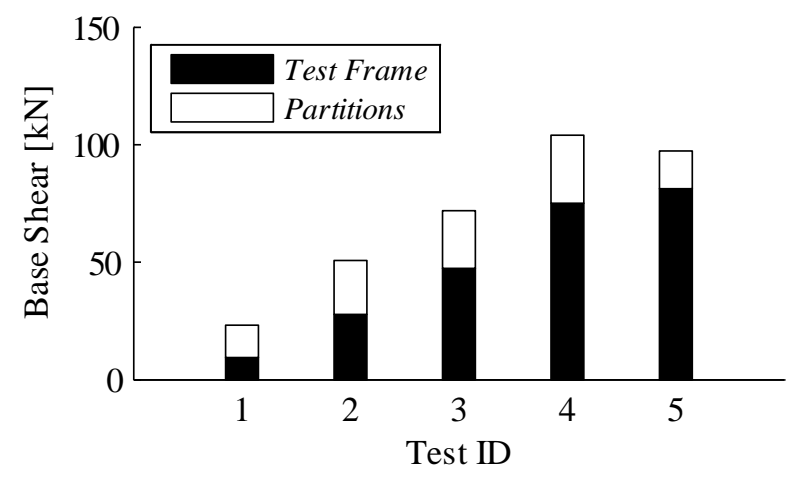

(a)

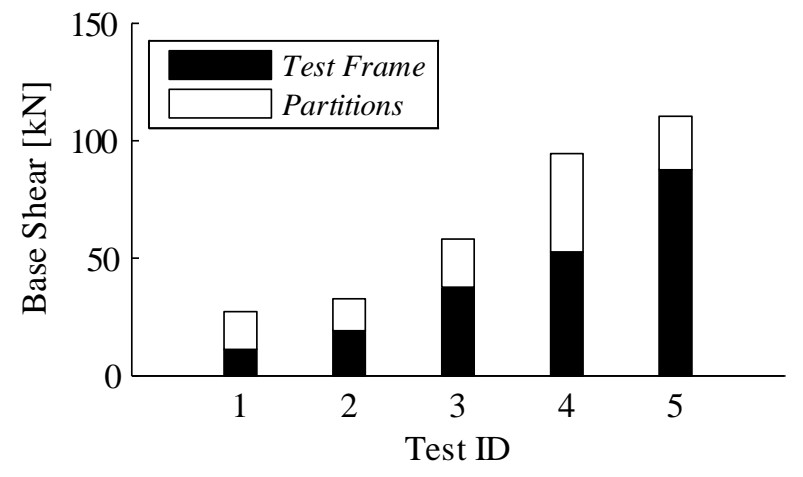

(b)

Fig. 13. Base shear distribution between test frame and partition systems for the different seismic tests in (a) $\mathrm{X}$ and (b) Y directions.

\subsection{Evaluation of the natural frequency of the component}

In order to evaluate the natural frequency in the out of plane direction, the transfer curve method is applied considering the base acceleration and the partition out of plane acceleration recorded by the accelerometer no. 6, placed in the centroid of the main partition (Fig. 5). The method is applied for the random vibration test in which the partition is shaken in the out of plane direction.

The transfer function in Fig. 14 yields two peaks: one at lower frequency, denoting the natural frequency in $\mathrm{X}$ direction of the test frame; the latter is related to the natural frequency of the nonstructural component in the out of plane direction. The frequency of the component is slightly larger than $30 \mathrm{~Hz}$.

The results confirm that the frequencies of the partitions are much larger than the typical structural fundamental frequencies. Hence, the ratio between the period of the nonstructural component $\left(T_{a}\right)$ and the period of the building $\left(\mathrm{T}_{1}\right)$, considered in Eurocode 8 [18] for the evaluation of the seismic demand on the component, could be accordingly assumed equal to zero.

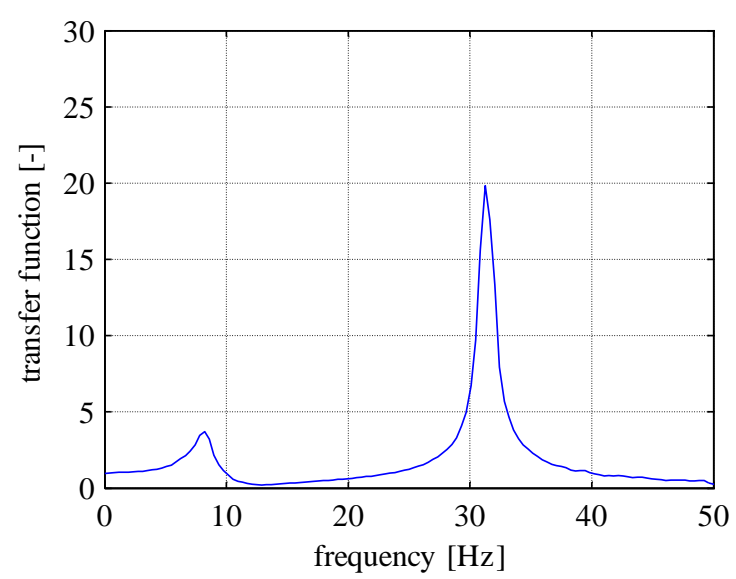

Fig. 14. Transfer function from the base to the partition center in the out of plane direction for the random vibration test.

\section{CONCLUSIONS}

Shaking table tests are carried out by the earthquake simulator facility available at the Department of Structures for Engineering and Architecture at the University of Naples Federico II in order to investigate the seismic behaviour of hollow brick internal partitions. The tested nonstructural component is widespread in the European area.

A steel test frame is adopted in order to simulate the seismic action acting at a generic building storey and the specimen boundary conditions. The tests are performed shaking the table simultaneously in both horizontal directions in order to subject the partition simultaneously to 
interstorey relative displacements in its own plane and accelerations in the out of plane direction. A set of five couples of accelerograms are selected matching the target response spectrum provided by the U.S. code for nonstructural components to investigate a wide range of interstorey drift demand and damage. Three damage states are considered in this study in order to characterize the seismic behaviour of the specimen. The dimensions of the specimen are adequately chosen in order to (a) test a realistic partition and (b) allow the investigation of the whole damage states range.

The hollow brick partition is subjected to interstorey drift up to $1.0 \%$. It exhibits minor damage for $0.2 \%$ interstorey drift, moderate damage for $0.34 \%$ interstorey drift and major damage for $0.97 \%$ interstorey drift.

Standard methods for the dynamic identification of the test setup are used in order to evaluate the influence of the hollow brick partitions on the steel test frame. The change in the natural frequency and the damping ratio during the different seismic tests clearly evidence the damage recorded in the specimen.

\section{ACKNOWLEDGEMENTS}

This research study has been funded both by Italian Department of Civil Protection in the framework of the national project DPC-ReLUIS 2010-2013 and by Siniat.

The authors also acknowledge the collaboration of MS engineers Marco Mastrovito and Marco Russo in the execution of experimental tests and in the analysis of the results.

\section{REFERENCES}

[1] Villaverde R. Seismic design of secondary structures: State of the art. J Struct Eng-Asce. 1997;123:1011-9.

[2] Bertero RD, Bertero VV. Performance-based seismic engineering: the need for a reliable conceptual comprehensive approach. Earthq Eng Struct Dyn. 2002;31:627-52.

[3] Taghavi S, Miranda E. Response assessment of nonstructural building elements, PEER report 2003/05. College of Engineering, University of California Berkeley, USA2003.

[4] Earthquake Engineering Research Institute (EERI). Nonstructural Issues of Seismic Design and Construction, Publication 84-04. Berkeley, CA, USA1984.

[5] Magliulo G, Pentangelo V, Maddaloni G, Capozzi V, Petrone C, Lopez P et al. Shake table tests for seismic assessment of suspended continuous ceilings. Bull Earthq Eng. 2012;10:1819-32.

[6] Badillo-Almaraz H, Whittaker AS, Reinhorn AM. Seismic fragility of suspended ceiling systems. Earthq Spectra. 2007;23:21-40.

[7] Gilani A, Reinhorn A, Glasgow B, Lavan O, Miyamoto H. Earthquake Simulator Testing and Seismic Evaluation of Suspended Ceilings. J Archit Eng. 2010;16:63-73.

[8] Magliulo G, Petrone C, Capozzi V, Maddaloni G, Lopez P, Manfredi G. Seismic performance evaluation of plasterboard partitions via shake table tests. Bull Earthq Eng. 2014:(online first) DOI: 10.1007/s10518-013-9567-8.

[9] Magliulo G, Petrone C, Capozzi V, Maddaloni G, Lopez P, Talamonti R et al. Shake Table Tests on Infill Plasterboard Partitions. Open Constr Build Technol J. 2012;6:155-63.

[10] Mosqueda G, Filiatrault A, Retamales R, Davies R, Fuchs J, Tian Y. Experimental Seismic Fragility of Steel Studded Gypsum Partition Walls and Fire Sprinkler Piping Subsystems. Structures Congress 2010 (ASCE)2010. p. 2633-44.

[11] Lee TH, Kato M, Matsumiya T, Suita K, Nakashima M. Seismic performance evaluation of non-structural components: Drywall partitions. Earthq Eng Struct Dyn. 2007;36:367-82.

[12] Magliulo G, Fabbrocino G, Manfredi G. Seismic assessment of existing precast industrial buildings using static and dynamic nonlinear analyses. Eng Struct. 2008;30:2580-8.

[13] Magliulo G, Capozzi V, Fabbrocino G, Manfredi G. Neoprene-concrete friction relationships for seismic assessment of existing precast buildings. Eng Struct. 2011;33:535-8. 
[14] Magliulo G, Petrone C, Capozzi V, Maddaloni G, Lopez P, Manfredi G. Seismic performance evaluation of plasterboard partitions via shake table tests. B Earthq Eng. 2013:(under review).

[15] Paulay T, Priestley M. Seismic design of reinforced concrete and masonry buildings. New York, US: Wiley; 1992.

[16] CEN. Eurocode 3: design of steel structures - Part 1-1: General rules and rules for buildings. EN 1993-1-1. Brussels, Belgium2005.

[17] CEN. Eurocode 3: design of steel structures - Part 1-8: design of joints. EN 1993-1-8. Brussels, Belgium2005.

[18] CEN. Eurocode 8: design of structures for earthquake resistance - Part 1: general rules, seismic actions and rules for buildings. EN 1998-1. Brussels, Belgium.2004.

[19] International Conference of Building Officials (ICBO). AC 156 Acceptance Criteria for the Seismic Qualification of Nonstructural Components. ICBO Evaluation Service, Inc., Whittier, California, USA2000.

[20] Federal Emergency Management Agency (FEMA). Interim protocols for determining seismic performance characteristics of structural and nonstructural components through laboratory testing. Report No. FEMA 461. Washington DC, US2007.

[21] Retamales R, Mosqueda G, Filiatrault A, Reinhorn A. Testing Protocol for Experimental Seismic Qualification of Distributed Nonstructural Systems. Earthq Spectra. 2011;27:835-56.

[22] International Code Council (ICC). International Building Code, 2000 Edition (IBC 2000). Falls Church, Virginia, USA. 2000.

[23] Maddaloni G, Magliulo G, Cosenza E. Effect of the seismic input on non-linear response of R/C building structures. Adv Struct Eng. 2012;15:1861-77.

[24] McKenna F, Fenves GL. OpenSees Manual http://opensees.berkeley.edu. Pacific Earthquake Engineering Research Center; 2013 (access date February 27, 2013).

[25] Panagiotakos TB, Fardis MN. Seismic response of infilled RC frames structures. In: International Association on Earthquake Engineering, editor. Eleventh World Conference on Earthquake Engineering. Mexico. 1996.

[26] Komaraneni S, Durgesh CR, Vaibhav S. Seismic Behavior of Framed Masonry Panels with Prior Damage When Subjected to Out-of-Plane Loading. Earthq Spectra. 2011;27.

[27] Tumialan J, Galati N, Nanni A. Field Assessment of Unreinforced Masonry Walls Strengthened with Fiber Reinforced Polymer Laminates. J Struct Eng. 2003;129:1047-56.

[28] Angel R, Abrams DP, Shapiro D, Uzarski J, Webster M. "Behavior of Reinforced Concrete Frames with Masonry Infills,” Structural Research Series 589, PhD thesis. Department of Civil Engineering, University of Illinois-Urbana, Urbana, IL. 1994. p. 236.

[29] Cohen E, Liang E. Discussion of “Arching theory of masonry Walls,” by E. L. McDowell, K. E. McKee, and E. Sevin. J Struct Div (ASCE). 1956;82:28-40.

[30] Dawe JL, Seah CK. Out-of-Plane Resistance of Concrete Masonry Infilled Panels. Can J Civil Eng. 1989;16:854-64.

[31] CEN. Eurocode 6: design of masonry structures - Part 1.3: general rules for buildings, detailed rules on lateral loading. ENV 1996-1-3. Brussels, Belgium. 2001.

[32] Flanagan RD, Bennett RM. Bidirectional behavior of structural clay tile infilled frames. J Struct Eng-Asce. 1999;125:236-44.

[33] Garbin E, Galati N, Nanni A. Design Guidelines for the Strengthening of Unreinforced Masonry Structures Using Glass Grid Reinforced Polymers (GGRP) Systems. Technical Report Prepared for Bondo Inc. \& TechFab LLC., University of Missouri-Rolla, Rolla, Missouri; 2005.

[34] Moghaddam H, Goudarzi N. Transverse Resistance of Masonry Infills. ACI Struct J. 2010;107:461-7.

[35] Dolatshahi KM, Aref AJ. Two-dimensional computational framework of meso-scale rigid and line interface elements for masonry structures. Eng Struct. 2011;33:3657-67.

[36] Oliveira DV, Lourenço PB. Implementation and validation of a constitutive model for the cyclic behaviour of interface elements. Computers \& Structures. 2004;82:1451-61. 
[37] Lourenço PB. Computational strategies for masonry structures. PhD Thesis. Delft University Press, Netherlands1996.

[38] Magliulo G, Capozzi V, Ramasco R. Seismic performance of R/C frames with overstrength discontinuities in elevation. Bull Earthq Eng. 2012;10:679-94.

[39] Magliulo G, Maddaloni G, Cosenza E. Extension of N2 method to plan irregular buildings considering accidental eccentricity. Soil Dyn Earthq Eng. 2012;43:69-84.

[40] Magliulo G, Ramasco R. Seismic response of three-dimensional r/c multi-storey frame building under uni- and bi-directional input ground motion. Earthq Eng Struct Dyn. 2007;36:164157.

[41] D'Ambrisi A, De Stefano M, Tanganelli M. Use of pushover analysis for predicting seismic response of irregular buildings: A case study. J Earth Eng. 2009;13:1089-100.

[42] Hashemi A, Mosalam KM. Shake-table experiment on reinforced concrete structure containing masonry infill wall. Earthq Eng Struct Dyn. 2006;35:1827-52.

[43] Chopra AK. Dynamics of structures: Theory and Applications to Earthquake Engineering. Englewood Cliffs, New Jersey, USA: Prentice Hall; 1995.

[44] Gabor D. Theory of communications. J Inst Elect Eng. 1946;93:429-57. 